\title{
The Predictive Effect of Mean Platelet Volume (MPV) and Neutrophil-to-Lymphocyte Ratio (NLR) on the Functional Outcome of Acute Ischemic Stroke
}

\author{
ABEER A. TONY, M.D.*; EFFAT A.E. TONY, M.D.**; WAFAA S. MOHAMMED, M.D.*** and \\ EMAD F. KHOLEF, M.D.***
}

The Departments of Neurology*, Internal Medicine ${ }^{* *}$ and Clinical Pathology***, Faculty of Medicine, Aswan*,*** and Assiut** Universities, Egypt

\begin{abstract}
Background: Inflammation has been reported to constitute a major component of ischemic stroke pathology. Nevertheless, to the best of our knowledge, no previous studies have investigated the NLR and MPV values in the cases of stroke stratified by subtype.
\end{abstract}

Aim of Study: The aim of our study is to predict the role MPV and NLR in short-term outcome in patients with ischemic stroke and their association to stroke severity, stroke risk factors and functional outcome.

Patients and Methods: This prospective cross sectional study directed on 125 patients with first time acute ischemic stroke. All members exposed to full history taking, detailed clinical examination and neurological checking. Brain imaging was performed after hospital admission. Blood tests were drawn for appraisal of the mean platelet volume (MPV) (in FL) and the neutrophil-lymphocyte ratio (NLR).

Results: Our results revealed that the mean value for NLR was higher in dead patients with ischemic stroke. By ROC curve, higher NLR at admission predicted the mortality than MPV. We found higher NLR levels in patients with more severe stroke. However, We did not observe a significant correlation between the MPV, the stroke severity, and outcome.

Conclusion: NLR was an independent risk factor and serves as a sensitive index for the prognosis of ACI patients. Further well-designed and large-scale prospective studies are necessary to evaluate platelet MPV and NLR for observing patients with cerebral infarction among different territories of Egypt and for stroke subtypes.

Key Words: Acute ischemic stroke - National Institutes of Health Stroke Scale (NIHSS) - Modified Rankin Scale $(m R S)$ - Mean platelet volume $(M P V)-$ Neutrophil/lymphocyte ratio (NLR).

\section{Introduction}

STROKE is the third leading cause of death after cardiovascular disorders and cancer while it ranks

Correspondence to: Dr. Abeer A. Tony, The Department of Neurology, Faculty of Medicine, Aswan University, Egypt first among disorders leading to disability worldwide [1]. Inflammation has been reported to constitute a major component of ischemic stroke pathology $[2,3]$. Ischemic brain injury secondary to an arterial occlusion, which is characterized by acute local inflammation and changes in levels of inflammatory cytokines was demonstrated [4] Recently, the neutrophil-to-lymphocyte ratio (NLR), platelet-to-lymphocyte ratio (PLR), and similar parameters (e.g., red blood cell distribution width [RDW] and mean platelet volume [MPV]), have been examined as a new expression of the inflammatory biomarkers in many diseases such as atherosclerosis, cerebral infarction and active inflammatory diseases [5-10]

MPV is a parameter detected during routine blood count and to which clinicians do not usually pay much attention. Platelet volume is known to be a marker determined from megakaryocytes during platelet production, which is associated with platelet function and activation [11]. Some studies have reported higher MPV values in patients with stroke and acute myocardial infarction than in control subjects [12-14]. The role of elevated MPV for predicting poor outcome of brain stroke was reported as independent to other clinical parameters such as lipid profile and other biochemical parameters [15].

NLR is the ratio of absolute neutrophil count to absolute lymphocyte count. NLR is a simple marker of subclinical inflammation and high NLR points to a predominance of inflammatory factors in the aetiopathogenesis of different conditions and possibly indicates subgroups of patients with similar disorder that will benefit from anti-inflammatory agents [16]. It has recently emerged as 
an independent useful prognostic marker to predict the mortality and prognosis of some cardiovascular and neurologic diseases [17-19]. Nevertheless, to the best of our knowledge, no previous studies have investigated the NLR and MPV values in the cases of stroke stratified by subtype. Thus, the aim of our study is to predict the role MPV and NLR in short-term outcome in patients with ischemic stroke and their association to stroke severity, stroke risk factors and functional outcome.

\section{Patients and Methods}

This cross-sectional prospective study conducted in the stroke unit of our neuropsychiatric Department, Faculty of Medicine, Aswan University from January 2017 to December 2017. It comprised 125 patients with first-ever acute ischemic stroke. Patients were eligible for inclusion if they were admitted to our unit with AIS defined according to the clinical evaluation of presence of focal neurological deficit of sudden onset that persisted beyond $24 \mathrm{hs}$ and confirmed by brain imaging (either CT scan and/or MRI brain). We excluded patients with intracranial hemorrhage, brain neoplasm, trauma, history of previous stroke, history of acute and chronic inflammatory diseases, malignancy, autoimmune diseases, renal or hepatic disease, history of use of anticoagulants or anticonvulsants and peripheral vascular diseases as well as those with a history of myocardial infarction $<3$ months.

The patients or their relatives gave written informed consent. A detailed medical and neurological history was taken and clinical and laboratory examinations were performed for all patients. The study was approved by ethics committee of our college.

\section{Clinical data collection and blood sampling:}

All patients will be submitted for Complete neurological examination where the following clinical and demographical data were taken; age, sex, stroke etiology, presence of stroke risk factors (as smoking history, hyperlipidemia, diabetes mellitus, history of hypertension, history of transient ischemic attacks, history of myocardial infarction or any cardiac problems). Stroke severity was assessed by National Institutes of Health Stroke Scale (NIHSS) measured at the time of admission. Functional outcome was assessed by Modified Rankin Scale (mRS) at admission and 90 days after admission. The favorable functional outcome of stroke patients was defined as mRS score of 0-2 (independent) and mRS score of 3-5 was disabled outcome while mRS score of 6 being dead. Brain imaging (either CT scan and/or MRI) was performed after admission. Electrocardiography (ECG), Echocardiography (ECHO), were done for all patients. Blood samples from all patients were drawn for assessment of complete blood picture (CBC), Random blood glucose levels, renal function tests (RFT), liver function tests (LFT), and Lipid profile using standard laboratory methods. $2 \mathrm{mls}$ of venous blood was aseptically collected into an EDTA vacutainer tube. Complete blood counts were done on the samples within six hours after phlebotomy. The samples were analyzed by Beckman Coulter LH 750 (Beckman Coulter, Miami, USA) hematology analyzers that provided MPV (in FL). The NLR was calculated by dividing the mean neutrophil counts by the mean lymphocyte counts.

\section{Statistical analysis:}

Data was collected and analyzed those using SPSS (Statistical Package for the Social Science, version 20, IBM, and Armonk, New York). Continuous data was expressed in form of mean \pm SD or median (range) while nominal data was expressed in form of frequency (percentage). Chisquare test was used to compare the nominal data of different groups in the study while student $t$ test was used to compare mean of different two groups and ANOVA test for more than two groups. Multivariate regression analysis was used to determine the independent risk factors for prediction of mortality in the studied patients. Diagnostic accuracy of MPC was determined by using ROC curve. $\mathrm{P}$ value was significant if $<0.05$.

\section{Results}

The study population included 125 patients with stroke, $68 \%$ were males and $32 \%$ were females. The mean age of included patients was $62.64 \pm 10.99$ years. Demographic, clinical characteristics and laboratory results of the study population were summarized in Table (1).

In univariate analysis, there was no significant differences between survivors and died as regarding $\mathrm{RBCs}, \mathrm{Hb}$, platelets count and mean platelets volume with $p>0.05$. However, the leucocytic count and neutrophil/lymphocyte (N/L) ratio values were found to increase significantly in dead patients ( $p=$ 0.02 and 0.03 respectively) Table (2).

ROC analysis was performed to determine the cut-off value of WBCs, Platelets, MPV and NLR in prediction of death within the studied patients. Table (3). Comparison of the area under curve revealed that NLR had the widest area under the 
curve ( $p=0.00$ ) Fig. (1). A N/L ratio of 4.99 or higher predicted the mortality with a sensitivity of $82.9 \%$ and a specificity of $78.9 \%$ as shown in Fig. (2).

The final logistic regression model showed that the only predictor for severity of cerebrovascular stroke based on national institute of health stroke scale was $\mathrm{N} / \mathrm{L}$ ratio $(\mathrm{OR}=1.99 ; 95 \% \mathrm{CI}=1.78-5.67$; $p=0.01)$ Table (4).

Based on NIHSS, 55 (44\%) patients had minor stroke while moderate and severe stroke presented in $35(28 \%)$ patients for each. It was noticed that

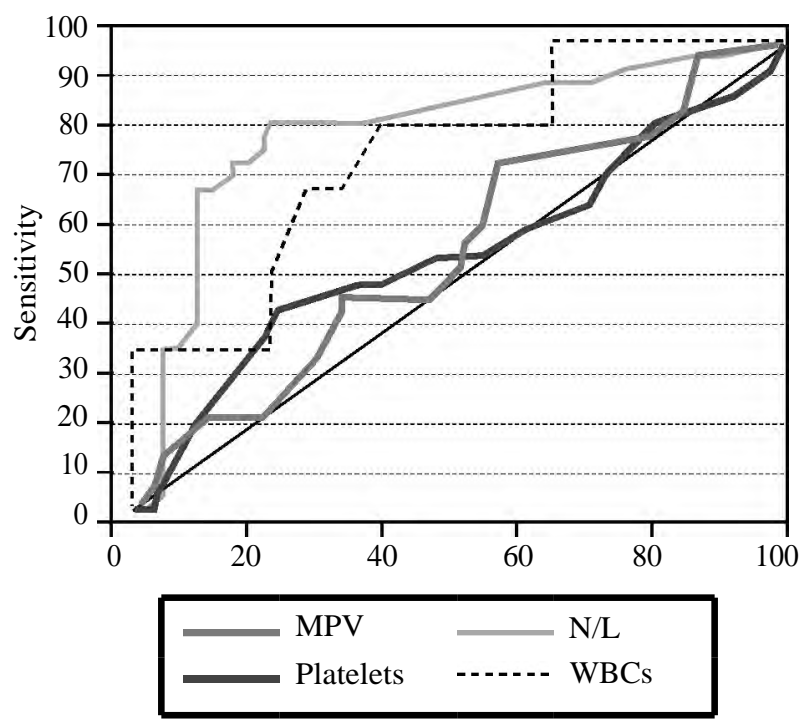

Fig. (1): ROC analysis for diagnostic indices of WBCs, Platelets, MPV and N/L for prediction of death in the study groups.

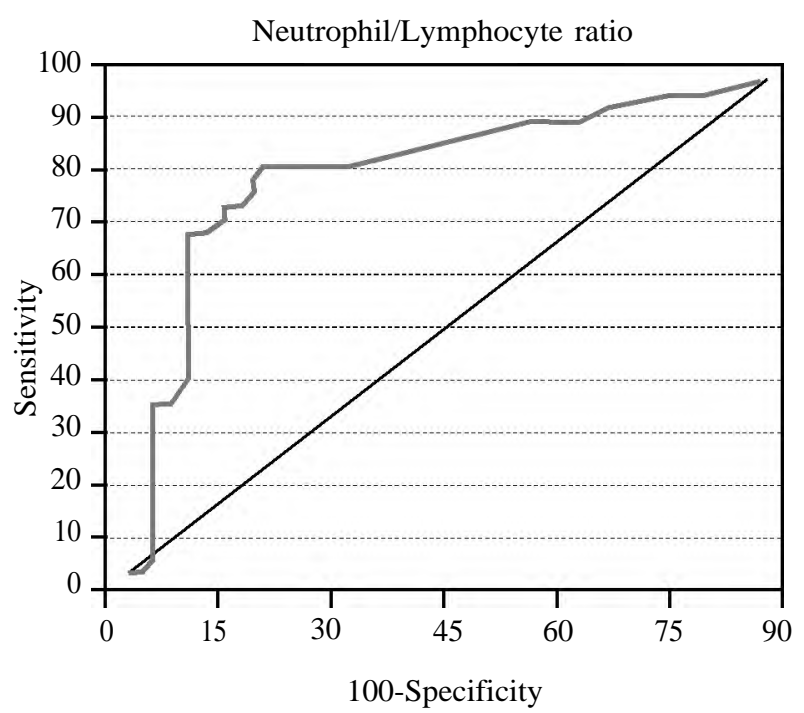

Fig. (2): ROC analysis for diagnostic indices of N/L for prediction of death in the study groups.
MPV had insignificant differences between different grades of the score $(p=0.94)$. However, N/L ratio was significantly higher in those patients with severe stroke $(p=0.03)$ (Table 5).

According to modified Rankin score (mRS), $17(13.6 \%), 15(12 \%), 33$ ( 26.4\%), $25(20 \%)$ and $35(28 \%)$ of our studied patients were slightly disabled, moderately disabled, moderately to severely disabled, severely disabled and died respectively. Although MPV had no significant changes between different grades of the score, N/L was significantly increasing as the score increased $(p=0.00)$ (Table 6).

Table (1): Characteristics of the studied patients with acute ischemic stroke: Serum Parameters and Mortality in the Study group.

\begin{tabular}{|c|c|}
\hline Parameters & Number $=125$ \\
\hline Age (years) Mean \pm SD & $62.64 \pm 10.99$ \\
\hline \multicolumn{2}{|l|}{$\operatorname{Sex}(N o \%)$ : } \\
\hline Male & $85(68 \%)$ \\
\hline Female & $40(32 \%)$ \\
\hline Duration of stroke (hours) Mean \pm SD & $4.34 \pm 1.04$ \\
\hline Modified Rankin scale (mRS) Mean \pm SD & $5.09 \pm 1.23$ \\
\hline NIHSS Mean \pm SD & $19.05 \pm 2.98$ \\
\hline Number of deaths $(\mathrm{No}, \%)$ & $35(28 \%)$ \\
\hline \multicolumn{2}{|l|}{ Vascular risk factors $(\mathrm{No}, \%)$ : } \\
\hline Hypertension & $71(64 \%)$ \\
\hline Dyslipidemia & $35(28 \%)$ \\
\hline Diabetes Mellitus & $32(28.8 \%)$ \\
\hline Smoking & $52(46.8 \%)$ \\
\hline Ischemic heart disease & $15(11.11 \%)$ \\
\hline Non valvular atrial fibrillation & $8(6.4 \%)$ \\
\hline Abnormal Carotid duplex (No,\%) & $75(60 \%)$ \\
\hline Abnormal Vertibrobasilar duplex (No,\%) & $18(14.4 \%)$ \\
\hline Laboratory Investigations & Mean \pm SD \\
\hline Red blood cells (x103/ml) & $4.99 \pm 0.65$ \\
\hline Hemoglobin level (g/dl) & $14.33 \pm 1.03$ \\
\hline Leukocytes $\left(\mathrm{x} 10^{3} / \mathrm{ml}\right)$ & $10.05 \pm 2.51$ \\
\hline Platelets count $\left(\times 10^{3} / \mathrm{ml}\right)$ & $260.11 \pm 63.45$ \\
\hline Mean platelet volume (fl) & $9.77 \pm 1.18$ \\
\hline Neutrophil/lymphocyte (N/L) ratio & $4.56 \pm 0.52$ \\
\hline Cholesterol (mg/dl) & $235.24 \pm 40.01$ \\
\hline Triglyceride (mg/dl) & $171.06 \pm 44.85$ \\
\hline HDL (mg/dl) & $47.43 \pm 13.56$ \\
\hline LDL (mg/dl ) & $104.76 \pm 23.98$ \\
\hline Random blood glucose (RBG) (mg/dl) & $167.66 \pm 44.87$ \\
\hline Erythrocyte sedimentation rate (ESR) & $55.09 \pm 12.43$ \\
\hline
\end{tabular}

Data was expressed in form of mean $\pm \mathrm{SD}$. 
Table (2): Correlation between different serum parameters and mortality in the study group.

\begin{tabular}{lllc}
\hline Parameters & Died $(\mathrm{n}=35)$ & Survivors $(\mathrm{n}=90)$ & $p$-value \\
\hline Red blood cells $\left(\mathrm{x} 10^{3} / \mathrm{ml}\right)$ & $5.07 \pm 0.32$ & $4.78 \pm 0.61$ & 0.39 \\
Hemoglobin level $(\mathrm{g} / \mathrm{dl})$ & $14.82 \pm 0.31$ & $14.17 \pm 1.85$ & 0.21 \\
Leukocytes $\left(\mathrm{x} 10^{3} / \mathrm{ml}\right)$ & $12.75 \pm 3.23$ & $8.74 \pm 2.02$ & 0.02 \\
Platelets count $\left(\mathrm{x} 10^{3} / \mathrm{ml}\right)$ & $263.08 \pm 70.55$ & $259.76 \pm 48.55$ & 0.34 \\
Mean platelet volume $(\mathrm{fl})$ & $9.63 \pm 1.02$ & $9.80 \pm 0.79$ & 0.56 \\
Neutrophil/lymphocyte $(\mathrm{N} / \mathrm{L})$ ratio & $5.95 \pm 0.39$ & $3.99 \pm 0.51$ & 0.03 \\
\hline
\end{tabular}

Data was expressed in form of mean $\pm \mathrm{SD} . \quad p$-value was significant if $<0.05 . \quad *$ Student $t$-test was used.

Table (3): Statistical diagnostic measures for the determined cut-off values of serum parameters in the detection of mortality.

\begin{tabular}{lccccccc}
\hline & AUC & Cut-off value & SEN & SPE & PPR & NPR & $p$-value \\
\hline WBCs & 0.76 & $>9.8$ & $82.9 \%$ & $62.2 \%$ & $46 \%$ & $90.3 \%$ & 0.09 \\
Platelets count & 0.56 & $>267$ & $42.9 \%$ & $77.8 \%$ & $42.9 \%$ & $77.8 \%$ & 0.34 \\
MPV & 0.55 & $>9$ & $74.3 \%$ & $44.4 \%$ & $34.2 \%$ & $81.6 \%$ & 0.29 \\
N/L & 0.81 & $>4.99$ & $82.9 \%$ & $78.9 \%$ & $60 \%$ & $92 \%$ & 0.001 \\
\hline$p$-value was significant if $<0.05$. & N/L : Neutrophil/ lymphocyte ratio'. & PPR: Positive predictive rate. \\
WBCs: White blood cells. & SEN: Sensitivity. & & NPR: Negative predictive rate. \\
MPV : Mean platelets volume. & SPE : Specificity. & & AR, AUC: Area under the curve.
\end{tabular}

Table (4): Multivariate logistic regression analysis for determining the role of MPV \& N/L ratio in predicting stroke severity by NIHSS.

\begin{tabular}{lccc}
\hline Variables & Odds Ratio & 95\% Confidence interval & $p$-value \\
\hline Age (year) & 1.2 & $2.1-3.68$ & 0.46 \\
Mean platelets volume (MPV) & 2.33 & $0.93-2.56$ & 0.45 \\
Neutrophil/lymphocyte ratio (N/L) & 1.99 & $1.78-5.67$ & 0.01 \\
\hline
\end{tabular}

$p$-value was significant if $<0.05 . \quad$ NIHSS: National institute of health stroke scale.

Table (5): Relation between MPV \& N/L and severity of stroke (on the basis of NIHSS).

\begin{tabular}{|c|c|c|c|c|}
\hline \multirow[b]{2}{*}{ Parameters } & \multicolumn{4}{|c|}{ NIHSS } \\
\hline & $\begin{array}{c}\text { Score 1-4: Minor } \\
\text { stroke }(\mathrm{n}=55,44 \%)\end{array}$ & $\begin{array}{l}\text { Score 5-14: Moderate } \\
\text { stroke }(n=35,28 \%)\end{array}$ & $\begin{array}{l}\text { Score 15-20: Severe } \\
\text { stroke }(\mathrm{n}=35,28 \%)\end{array}$ & $p$-value \\
\hline MPV (fl) & $9.99 \pm 0.75$ & $9.21 \pm 1.11$ & $10.01 \pm 0.67$ & 0.94 \\
\hline $\mathrm{N} / \mathrm{L}$ ratio & $4.34 \pm 0.22$ & $5.01 \pm 0.18$ & $6.22 \pm 0.33$ & 0.03 \\
\hline
\end{tabular}

Table (6): Relation between MPV \& N/L ratio and functional outcome of patients with stroke (on the basis of Modified Ranking's score mRS).

\begin{tabular}{lcccccc}
\hline & \multicolumn{5}{c}{ Modified Rankin's Score (mRS) } \\
\cline { 2 - 7 } Parameters & $\begin{array}{c}\text { Score 2: Slight } \\
\text { disability } \\
(\mathrm{n}=17,13.6 \%)\end{array}$ & $\begin{array}{c}\text { Score 3: } \\
\text { Moderate disability } \\
(\mathrm{n}=15,12 \%)\end{array}$ & $\begin{array}{c}\text { Score 4: } \\
\text { Moderately } \\
\text { severe disability } \\
(\mathrm{n}=33,26.4 \%)\end{array}$ & $\begin{array}{c}\text { Score 5: } \\
\text { Severe disability } \\
(\mathrm{n}=25,20 \%)\end{array}$ & $\begin{array}{c}\text { Score 6: Death } \\
(\mathrm{n}=35,28 \%)\end{array}$ & $p$-value \\
\hline MPV (fl) & $9.03 \pm 0.9$ & $8.93 \pm 1.11$ & $9.62 \pm 079$ & $9.13 \pm 1.1$ & $9.63 \pm 1.02$ & 0.45 \\
N/L ratio & $3.99 \pm 0.12$ & $3.92 \pm 0.51$ & $4.1 \pm 0.93$ & $4.05 \pm 0.44$ & $5.95 \pm 0.39$ & 0.001 \\
\hline
\end{tabular}

Data was expressed in for of mean SD and $p$-value was significant if $<0.05$.

n: Number. MPV: Mean platelets volume. N/L: Neutrophil leukocyte ratio. 


\section{Discussion}

Studies on NLR and MPV have grown recently following the discovery of their immense values in prediction and prognosis of many medical conditions. These parameters are potent markers of inflammation which underlies the basic pathologies of various diseases. The easy of availability of these parameters without additional costs to the patients may gradually replace the older markers of inflammation [16].

Our result revealed that the mean value for NLR and total lecuocytic count are higher in the patients with ischemic stroke who died in comparison to those who survived ( $p=0.03)$. Celikbilek etal reported that NLR is a novel index for cerebral infarction regardless of classical cardiovascular risk factors. Also, it predicts poor prognosis in ischemic cerebrovascular disease [20]. Also, In a study in Turkey with patients who presented to the emergency service with cerebrovascular accident (stroke and transient ischemic attack), the NLR was significantly higher in patients who died $(p, 0.001)$ and in those with ischemic or hemorrhagic stroke than in those with transient ischemic attack $(p, 0.001)[21]$.

In our study, an NLR of 4.99 or higher at admission was predicted the mortality with a sensitivity of $82.9 \%$ and a specificity of $78.9 \%$. The predictive value of NLR in the detection of mortality compared to WBCs, Platelets, MPV was described in this study by a wider area in the ROC curve (AUC 0.81) than that of WBCs (AUC 0.76), Platelets (AUC 0.56) and MPV (AUC 0.55). In accordance with the presented results, several authors reported that the NLR is an independent mortality predictor in the short and long term [19, 22, 23]. NLR levels were found higher in patients with moderate/severe stroke than in patients with minor stroke (OR 1.99, $p=0.01$ ). This result support the hypothesis that NLR is a good predictive factor of stroke and stroke prognosis [24].

In this study, We did not observe a significant correlation between the MPV, the stroke severity, and outcome. Previous studies show inconsistent results; some studies have found a relation between high MPV level and high risk of stroke [25-27] However, there are also studies in which such association was not found [28,29].

There are limited data about the effect of pharmacological therapy on platelet count and size. A randomized controlled trail measured a lower MPV level after 4 weeks of antiplatelet drugs treatment [30]. Since the patients included in our study had at least one background disease (hypertension, diabetes mellitus, atrial fibrillation, etc.), some of them may have been under antiplatelet drugs treatment at the time of admission, a fact that could have affected their MPV level. Another explanation to the inconsistency in the results is the very poor standardization of the methodologies used for MPV measurement which vary from device to device [31]. In addition, MPV can be influenced by the time interval between sampling and analysis [32] MPV results become increasingly unreliable after 4h [33] . Complete blood count analysis in our laboratory has almost proceeded within $4 \mathrm{~h}$ from sampling start.

The interpretation of this study has some limitations. First, We did not measure the level of inflammatory markers, such as TNF-a, IL-6, and CRP. Therefore, we did not compare the prognostic value of the NLR and those inflammatory factors. Second, we did not detect the location of cerebral infarction, this fact could affect the results since the severity of stroke was determined by the NIHSS, which has a good correlation with the middle cerebral artery infracts but underestimates severity of posterior circulation strokes [34]. Despite these limitations, our study has important clinical implications of that the presence of a high NLR at admission in acute cerebral infarction has predictive value for stroke and stroke prognosis. This simple, inexpensive, and widely available biomarker that can be attainable by using an automatic haematology analyser can offer an additional noninvasive tool for risk stratification to assess the severity and prognosis of cerebral infarction.

\section{Conflict of interest:}

There is no conflict of interest in this work.

\section{References}

1- DEB P., SHARMA S., HASSAN K.M.: Pathophysiologic mechanisms of acute ischemic stroke: An overview with emphasis on therapeutic significance beyond thrombolysis. Pathophysiology, (17): 197-218, 2010.

2- JIN R., YANG G., and LI G.: Inflammatory mechanisms in ischemic stroke: Role of inflammatory cells. J. Leukoc. Biol., 87: 779-789, 2010.

3- JIN R., LIU L., ZHANG S., NANDA A. and LI G.: Role of inflammation and its mediators in acute ischemic stroke. Journal of Cardiovascular Translational Research., Volume 6, Issue 5, pp 834-851, 2013.

4- NAYAK A.R., KASHYAP R.S., KABRA D. and DEORAS P.: Evaluation of routinely performed hematological and biochemical parameters for the prognosis of acute ischemic stroke patients. Neurological Sciences, 32: 855, 2011.

5- CANPOLAT F., AKPINAR H. and ESKIOGLU F.: Mean platelet volume in psoriasis and psoriatic arthritis. Clin. Rheumatol., 29: 325-8, 2010. 
6- TANG W.B., LI M.X., LI G.Q., et al.: Changes of mean platelet volume, fibrinogen content and blood rheology in peripheral blood of youth patients with cerebral infarction. Zhongguo Shi Yan Xue Ye Xue Za Zhi, 20: 3903, 2012.

7- MURAT S.N., DURAN M., KALAY N., et al.: Relation between mean platelet volume and severity of atherosclerosis in patients with acute coronary syndromes. Angiology, 64: 13 1-6, 2013.

8- AFARI M.E. and BHAT T.: Neutrophil to lymphocyte ratio (NLR) and cardiovascular diseases: an update. Expert. Rev. Cardiovasc. Ther., 14: 573-77, 2016.

9- BALTA S., CELIK T., MIKHAILIDIS D.P. et al: The relation between atherosclerosis and the neutrophillymphocyte ratio. Clin. Appl. Thromb. Hemost., 22 (5): 405-11, 2016.

10- KIM D.S., SHIN D., LEE M.S. et al: Assessments of neutrophil to lymphocyte ratio and platelet to lymphocyte ratio in Korean patients with psoriasis vulgaris and psoriatic arthritis. J. Dermatol., 43: 305-10, 2016.

11- GASPARYAN A.Y., AYVAZYAN L., MIKHAILIDIS D.P. and KITAS G.D.: Mean platelet volume: a link between thrombosis and inflammation? Curr Pharm Des. 17 (1): 47-58, 2011.

12- MUSCARI A., PUDDU G.M., CENNI A., SILVESTRI M.G., GIUZIO R., ROSATI M. et al.: Mean platelet volume (MPV) increase during acute non-lacunar ischemic strokes. Thromb. Res., 123: 587-91, 2009.

13-VIZIOLI L., MUSCARI S., MUSCARI A.: The relationship of mean platelet volume with the risk and prognosis of cardio-vascular diseases. Int. J. Clin. Pract., 63: 1509$1515,2009$.

14- MAYDA-DOMAÇ F., MiS1RL1 H. and Y1LMAZ M.: Prognostic Role of Mean Platelet Volume and Platelet Count in Ischemic and Hemorrhagic Stroke. J. Stroke. Cerebrovasc. Dis. Jan., 19 (1): 66-72, 2010.

15- GREISENEGGER S., ENDLER G., HSIEH K., TENTSCHERT S., MANNHALTER C. and LALOUSCHEK W.: Is elevated mean platelet volume associated with a worse outcome in patients with acute ischemic cerebrovascular events? Stroke., 35: 1688-91, 2004.

16- ALEXANDER N.I.: Reference Values of NeutrophilLymphocyte Ratio, Platelet-Lymphocyte Ratio and Mean Platelet Volume in Healthy Adults in North Central Nigeria. J. Blood Lymph., 6: 143. doi:10.4172/2165-7831.1000143, 2016.

17- TOKGOZ S., KAYRAK M., AKPINAR Z., SEYITHANOGLU A., GÜNEY F. and YÜRÜTEN B.: Neutrophil lymphocyte ratio as a predictor of stroke. J. Stroke. Cerebrovasc. Dis., 22 (7): 1169-1174, 2013.

18- SALIBA W., BARNETT-GRINESS O., ELIAS M. and RENNERT G: Neutrophil to lymphocyte ratio and risk of a first episode of stroke in patients with atrial fibrillation: A cohort study. J. Thromb. Haemost., 13: 1971-9, 2015.

19- WANG F., HU S., DING Y., et al.: Neutrophil-tolymphocyte ratio and 30-day mortality in patients with acute intracerebral hemorrhage. J. Stroke. Cerebrovasc Dis., 25 (1): 182-187, 2016.

20- CELIKBILEK A., ISMAILOGULLARI S. and ZARARSIZ G.: Neutrophil to lymphocyte ratio predicts poor prognosis in ischemic cerebrovascular disease. J. Clin. Lab. Anal., 28: 27-31, 2014.

21- GÖKHAN S., OZHASENEKLER A., MANSUR DURGUN H., AKIL E., USTÜNDAG M. and ORAK M. Neutrophil lymphocyte ratios in stroke subtypes and transient ischemic attack. Eur. Rev. Med. Pharmacol. Sci., 17 (5): 653-657, 2013.

22- TOKGOZ S., KESKIN S., KAYRAK M., SEYITHANOGLU A. and OGMEGUL A.: Is neutrophil/lymphocyte ratio predict to short-term mortality in acute cerebral infarct independently from infarct volume? J. Stroke. Cerebrovasc. Dis., 23 (8): 2163-2168, 2014.

23- BROOKS S.D., SPEARS C., CUMMINGS C., et al Admission neutrophil-lymphocyte ratio predicts 90 day outcome after endovascular stroke therapy. J. Neurointerv. Surg., 6 (8): 578-583, 2014.

24- FARAH R. and SAMRA N.: Mean platelets volume and neutrophil to lymphocyte ratio as predictors of stroke. J. Clin. Lab. Anal., 32: e22189, 2018

25- BATH P., ALGERT C., CHAPMAN N. and NEAL B.: Association of mean platelet volume with risk of stroke among 3134 individuals with history of cerebrovascular disease. Stroke. A Journal of Cerebral. Circulation., 35: 622-626, 2004.

26- GHAHREMANFARD F., ASGHARI N., GHORBANI R., et al.: The relationship between mean platelet volume and severity of acute ischemic brain stroke. Neurosciences (Riyadh)., 18: 147-151, 2013.

27- LI B., LIU X., CAO Z-G., LI Y., LIU T-M. and WANG R-T.: Elevated mean platelet volume is associated with silent cerebral infarction. Internal Medicine Journal, 653657,2014

28- NTAIOS G., GURER O., FAOUZI M., AUBERT C. and MICHEL P.: Mean platelet volume in the early phase of acute ischemic stroke is not associated with severity or functional outcome. Cerebrovasc. Dis., 29: 484-489, 2010.

29- OZ I.I., YUCEL M., BILICI M., et al.: Is mean platelet volume a reliable marker to predict ischemic stroke in the follow-up of patients with carotid stenosis? J. Stroke. Cerebrovasc. Dis., 25: 404-409, 2015.

30- HAUNGSAITHONG R., UDOMMONGKOL C., NIDHINANDANA $S$., et al.: The changes in mean platelet volume after using of antiplatelet drugs in acute ischemic stroke: a randomized controlled trial. J. Med. Assoc. Thai., 98: 852-857, 2015

31- BEYAN C.: Is mean platelet volume a predictive marker in patients with venous thrombosis? Clin. Appl. Thromb. Hemost., 18: 670-1, 2012.

32- MACHIN S.J., BRIGGS C.: Mean platelet volume: A quick, easy determinant of thrombotic risk? J. Thromb. Haemost., 8: 146-7, 2010.

33- BRUMMITT D.R. and BARKER H.F.: The determination of a reference range for new platelet parameters produced by the Bayer ADVIA120 full blood count analyser. Clin. Lab. Haematol., 22: 103-7, 2000.

34- LINFANTE I., LLINAS R.H., SCHLAUG G., CHAVES C., WARACH S. and CAPLAN L.R.: Diffusion-weighted imaging and National Institutes of Health Stroke Scale in the acute phase of posterior-circulation stroke. Arch. Neurol., 58: 621-628, 2001. 


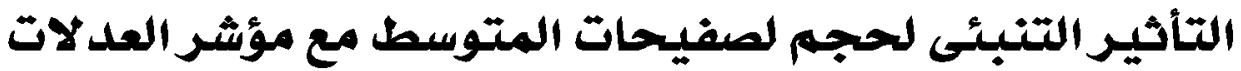

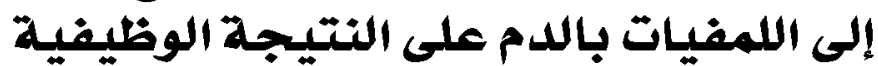

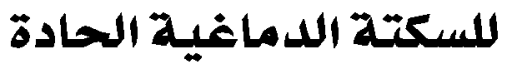

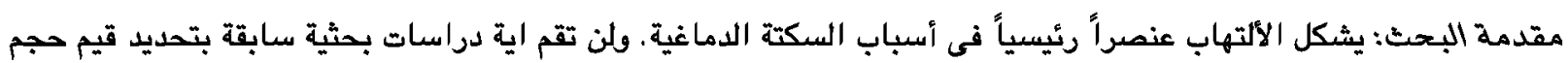
الصفيحات المتوسط مع مؤثر العدلات إلى اللمفيات بالدم فى حالات العات السكتات الدماغية الطبقية حسب نوعها.

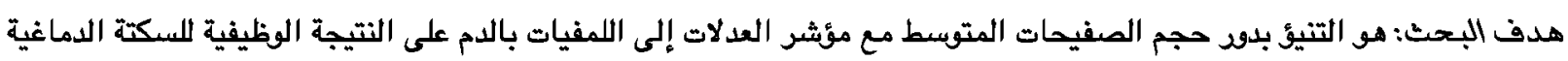

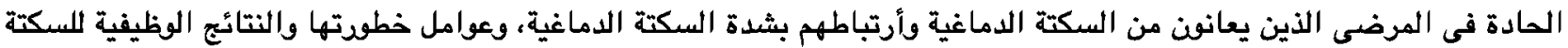
الدماغية الصادة.

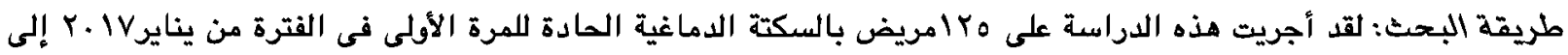

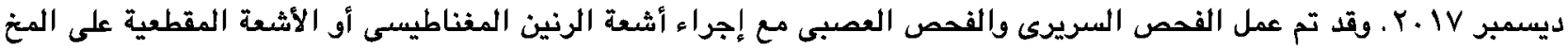

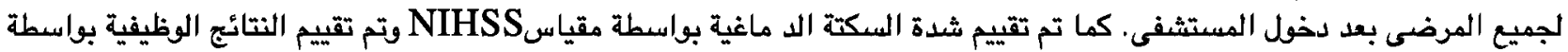

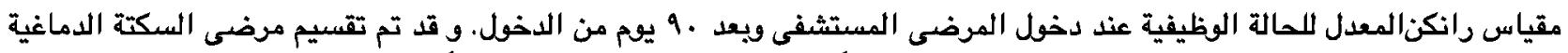

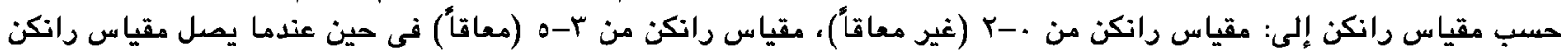

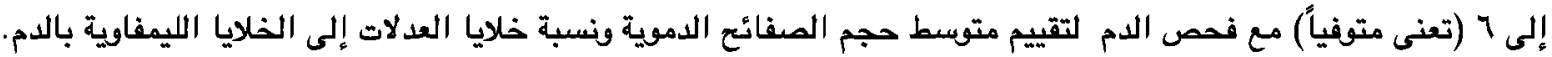

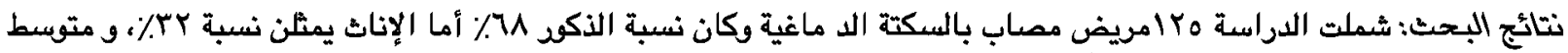

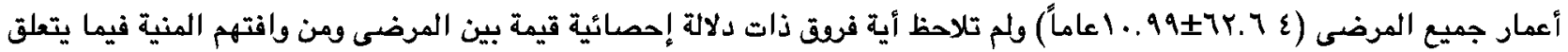

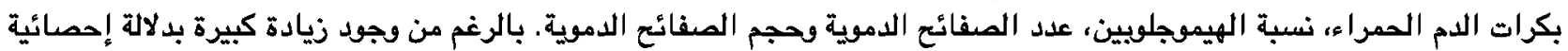

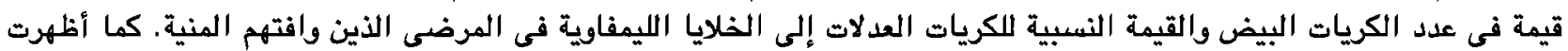

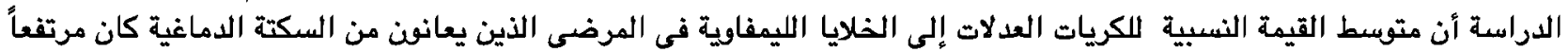

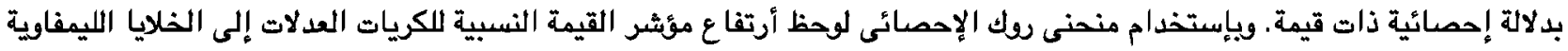

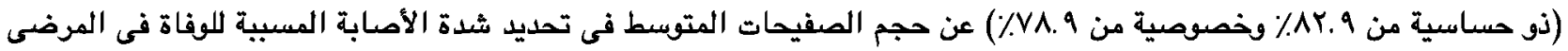

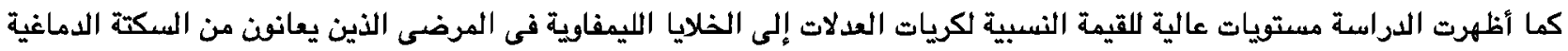

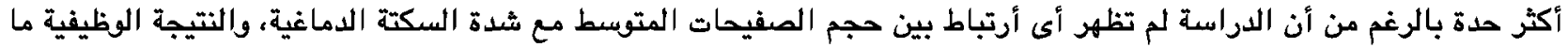

بعد الإصابة.

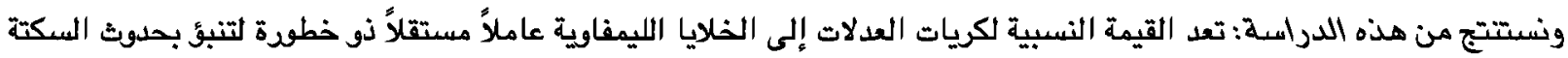

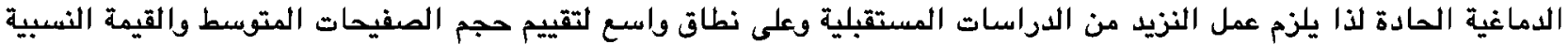

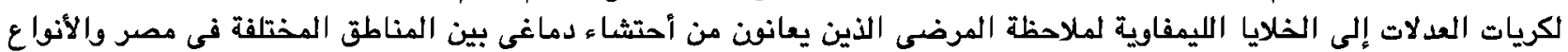

